\title{
Introduction: Developing an approach to writing as material practice
}

\author{
Kathryn E. Piquette and Ruth D. Whitehouse \\ Freie Universität Berlin and University College London
}

\begin{abstract}
Scope and Impetus
This book grapples with the issue of writing and related graphical modes as forms of material culture. The diverse case studies are unified and underpinned by the notion that writing is fundamentally material - that it is preceded by and constituted through the material practices of human practitioners. From this vantage point, understandings of things that are written must therefore go beyond study of textual meanings and take account of the material worlds in which writing is inextricably embedded. In aligning along this common theme, analytical and interpretive priority is given, not to the linguistic and semantic meanings of graphical marks, but to their physicality and the ways in which this relates to creators and users. Covering a temporal span of some 5000 years, from c.3200 BCE to the present day, and ranging in spatial context from the Americas to the Near East, the papers bring a variety of perspectives which contribute to both specific and broader questions of writing, its meaning and significance. As such, these case studies also contribute to an emerging discourse (below) on 'writing' and 'materiality'. They also contribute to the development of contextualising paradigms equipped to cope with the complexities of graphical cultures in relation to the people who created and attributed meaning to them through a diverse array of individual and wider social practices.

While an increasing emphasis on materiality has characterised many fields of archaeological research over the last 20 years, studies of writing have lagged behind in this respect. The main reason is a long established and difficult-to-shift disciplinary division between archaeology and philology, in which the philologists - often brought in by archaeologists as technical experts whose interpretations are hard to challenge - have had the upper hand. This has led to an
\end{abstract}

\section{How to cite this book chapter:}

Piquette, K. E. and Whitehouse, R. D. 2013. Introduction: Developing an approach to writing as material practice. In: Piquette, K. E. and Whitehouse, R. D. (eds.) Writing as Material Practice: Substance, surface and medium. Pp. 1-13. London: Ubiquity Press. DOI: http://dx.doi. org/10.5334/bai.a 
emphasis on the content of inscriptions and other writing, concentrating on languages, scripts and the semantic meanings of texts. These studies not only neglect materiality, which is our focus here, but they also tend to neglect context (both the specific archaeological context of the artefact, and the broader cultural and historical context into which written surfaces fit). Studies of content, context and materiality are all necessary for a holistic study of writing and many of the papers in this volume, while concentrating on material aspects of writing, do also deal with the meaning of the texts being studied and the contexts of their production and use.

Our concern with the question of writing artefactuality was prompted by methodological problems arising out of our own research on ancient writing (e.g. Piquette 2007; 2008; 2013; forthcoming; Whitehouse 2008; 2012). Our interest in exploring writing materialities cross-culturally is also inspired by the work of several scholars who also challenge the traditional disciplinary division between archaeology and philology (e.g. Moreland 2001; 2006; cf. Bottéro 1992; 2000). “Textaided archaeology" (Hawkes 1954; see also Little 1992) and discussions of text and archaeology come closer to providing integrated understandings of the written pasts but nevertheless embody a paradigm where text is a largely immaterial source about the past. Moreland and others have highlighted the methodological drawbacks of de-materialising treatments of written objects, and while a gradual 'material turn' is underway in some areas (Andrén 1998; Gardner 2003: especially 2, 6; Matthews 2003: 56-64), an emphatic disciplinary-wide shift to a more holistic and inclusive framework has yet to be realised - whether from philological or archaeological points of departure. We therefore sought to contribute momentum to this shift by convening a conference of the same title in 2009 and assembling this edited volume of many of the papers delivered at that meeting. We feel this represents an important step towards focussing and stimulating a more sustained engagement with this theme, within archaeological discourse, textual studies, and hopefully beyond. Before outlining the contents of the volume we would like to briefly discuss the three key terms which bind the papers together, namely 'writing', 'material', and 'practice'.

\section{Writing}

Contributors to this volume address the subject of 'writing' in a broad sense, including writtentext and signs taken to represent units of language as well as marking systems that are less clearly related to spoken language, although the former dominate. Ontologically writing is treated as both a process and an outcome; authors distinguish the act of writing from the result of that action to explore how aspects of production and consumption actively constitute written meanings. The notion of meaning as unfolding in particular times and places, as part of a socially-situated chaîne opératoire, challenges the conventional epistemological role often assigned to writing as a source about the past (Moreland 2006: 137-138, 143). Papers thus focus on writing as an integral part of cultural practice and demonstrate that this data type not only augments archaeological reconstruction of the past, but can fruitfully be studied as material culture and as an active constituent of the past - just as it continues to be so profoundly in the present (below).

\section{Materials: Writing as artefact}

Essential to achieving the paradigmatic shift whereby writing is understood as wholly embedded in, and a dynamic constituent of social worlds, is the theorisation of the 'material' in written culture. Linked to this is the relationship of material to past embodied writers, readers and others involved in the production and consumption of written objects. A conceptual framework that we found useful in developing the volume (and conference) theme is expressed in the second part of the volume title: substance, surface and medium. ${ }^{1}$ 
These are the components of a tri-partite model for material properties developed by American Psychologist James Gibson in his book The Ecological Approach to Visual Perception (1979: especially chapter 6). His framework is not explicitly directed to writing, but it nevertheless provides a useful guide for examining the significance of the marks of writing in relation to the material surfaces on which they occur - and importantly - their multisensory perception by humans in different environmental conditions (see also Ingold 2007).

Taking as example the inscription of a lead curse tablet from the Roman site of Uley, in Gloucestershire, England (Figure 1): its particular material substance of lead, the semi-smoothness of the hammered metal surface punctuated by impressions cum incisions as formed by pressing and dragging a stylus into and across its surface, and the environmental medium of, for example, lamp or candlelight, come together to provide certain 'affordances' or opportunities for visual perception and other sensory and bodily interactions. Whether viewing, touching, carving, incising, applying ink and so on, writing acts are directly informed by material properties. Of course, they are also mediated to varying extents by cultural knowledge (e.g. tacit, explicit) for a given mark-making system - conventions of script production and meaning to both creator and intended / unintended audiences. The material results of specific actions - the subtractive and additive marks or other types of surface transformations encountered on a range of artefacts and surfaces - deserve documentation, study and explanation alongside palaeographical, philological, linguistic, and historical analyses. The case studies in this volume highlight the kinds of additional insight gained by investigating substance, surface and medium (albeit variously defined), and their implications for the content meaning of writing. Moreover, this focus on material properties encourages clearer articulation and reflexive consideration of the distinction between graphical evidence as a source about the past, and how an object was also constitutive of that past (Moreland 2001; 2006).

Writing played an active and meaningful role in the construction of past social lives, the material constitutive nature of which is raised emphatically by Gibson's triad. It also makes imperative setting materials in relation to human perception. Perception of material surfaces is thus an embodied process which unfolds in time and space; practice is implicated at its very core. Given that material substances and their surfaces can only be put to use as writing spaces through bodily action, and can only be identified as writing through sensory perception, it is clear that the concepts of practice must be central to a material approach to written evidence.

The term 'material' is conceptualised in variable ways in the volume's chapters, but overall it refers to the stuff on which writing appears, and for additive techniques that which physically constitutes written marks. The term 'materiality' can be unhelpful if it is simply used as a substitute for 'material' (see Ingold 2007). However, we suggest it can be useful for distinguishing between a necessarily passive notion of 'material' (substance) that precedes analysis and interpretation, and a more active concept involving material as incorporated subsequently into a narrative of socially situated marking practices. 'Materiality' can thus refer in a general way to the material aspects of artefacts, while also, and importantly, prompting their situation in relation to mutually-informing sets of practices. This enables material to be described as more than a mere 'support' for writing. It becomes active in the construction of meanings, from the preliminary work of manufacturing artefact 'blanks' on which marks are made, and the techniques of surface transformation which give rise to written marks, to the ways in which these physical objects were incorporated into subsequent activities, from reading / viewing (where intended) and display, to discard, deposition or loss. In addition to seeing writing as meaningful through the materiality of its expression, the papers in this volume also advocate study of the way the written is bound up in individual and group interactions and perceived cultural norms, and how these are reproduced or renegotiated. 

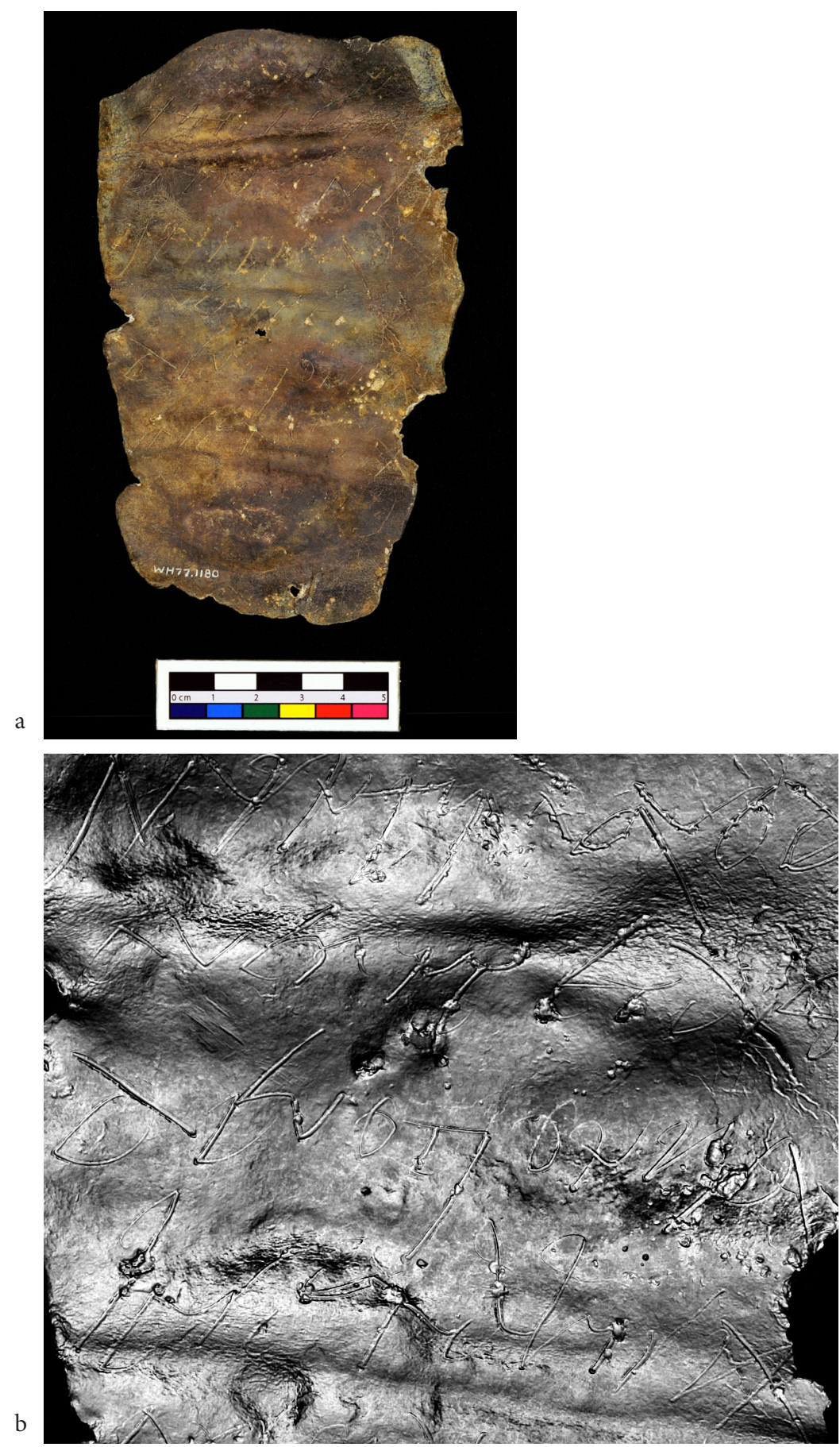

Figure 1: a) Incised lead tablet bearing a curse written in the Roman Imperial period. From the Uley Shrines, West Hill, Gloucestershire (Woodward and Leach 1993: 118, No. 1). WH77.1180, British Museum; b) Detail derives from Reflectance Transformation Imaging (RTI) visualisation using the 'specular enhancement' rendering mode to clarify ductus and surface transformations made by the writer's stylus and other surface morphology. Photograph and RTI detail Kathryn E. Piquette, Courtesy Roger Tomlin and Trustees of the British Museum. 


\section{Practice: Text as process and outcome}

Practice is another conceptual theme which underpins the studies in this volume. Theoretical approaches to practice (e.g. Bourdieu 1977; Foucault 1979; Giddens 1979; 1984) have been brought to bear on the study of archaeological data for more than three decades (e.g. David and Kramer 2001; Dobres 2000). A dominant concern among these studies has been with technology and charting innovation, change, and continuity. Particular emphasis has been placed on agency, identity, and the body, but in keeping with traditional disciplinary divisions, writing has been largely omitted from this discourse. The recognition engendered by a material practice perspective - that the act of writing and its material products are fundamentally technological - makes it incumbent upon archaeologists to study the marks of inscription in the same way that lithic, ceramic or other types of data are examined.

Similar to analyses of these archaeological data types (Schlanger 1996; Tite 2008), it follows that explanatory frameworks developed for studies of mark-making should also incorporate theories of practice. Etienne Wenger's concept of "communities of practice", with its emphasis on learning, and participation and reification (1998: 58-62), offers ways for exploring writing on the levels of both individual and collective practice. Practices are reified, or not, depending on accumulations of individual participation. Reification in everyday life may remain abstract in its manifestation, such as the practice of taking a tea break at an appointed time or shaking hands upon meeting, but reification also shapes experience and meaning in more materially enduring ways. The computer and printing technologies used to produce this volume constitute the nature of writing and reify a particular view of it materially, in contrast to many of the writing practices addressed in the contributions themselves. The concept of "communities of practice" draws on Anthony Giddens' notion of "structuration" - the negotiation of the relationship between individual agency and social structures through situated practice. This concept of agency as constituted by, and constituting of, social structure ensures a framework for understanding practice that is neither overindividualising nor over-generalising (cf. Gardner 2004: 2-4 with e.g. Barrett 2001: 149; Hodder 2000: 25).

While a concept of agency that is set in relation to social structure can be fruitful for explaining how individuals choose to act and participate (or not) in writing cultures (see Piquette 2013), archaeological theory is also well-equipped to provide new explanatory frameworks for addressing writing in the context of bodily practice. One direction in which engagement with material practice leads us is a concern for the senses, through which human beings experience the material world. The broader spectrum of human sensory experience of past materialities has been investigated within archaeology since the early 1990s and has become more prominent in recent years (Fahlander and Kjellström 2010; Skeates 2010), albeit with limited concern for past writing. The emergence of Visual Cultural Studies during the late 1980s as its own discipline, and the field of Image Studies as well (Mitchell 2002: 178), represents an important move to treat imagery and its materiality from a more multisensory perspective (Jay 2002: 88; despite the visual bias implied in its name), but here too writing has been sidelined. Perhaps some insight into why certain barriers persist for work across some disciplinary boundaries is required. Marquard Smith (2008: 1-2) makes an interesting observation with regard to publication in his discipline, Visual Cultural Studies, which parallels our experience in bringing this volume to press. It is commonplace to encounter numerous books with 'visual' and 'culture' in the title in university libraries, bookshops or online booksellers, but where they are shelved or how they are otherwise categorised ranges widely. From Art History, Aesthetics and Anthropology to Critical Theory or Sociology, no one is quite sure where to put visual culture or where to find it. The present volume seemed to present a similar classificatory conundrum (and thus marketing difficulties according to one publisher we approached). The ontological challenge presented by the notion of writing as object, and an object that is embedded within the full spectrum of human sensory experience, presents an interesting 
paradox. If one pauses to survey one's surroundings, graphical culture of all sorts is clearly embedded in the material world. In the present day we cope easily with the interweaving of writing and associated image types in day-to-day life. Whether we are checking text messages on a phone, flicking through a magazine, licking a stamp, struggling to unfurl a newspaper on a crowded bus, or reading this very text as part of a paper-based or e-book, it is easy to see how these material contexts and sensory experiences beyond the visual are important to writing-related practices and meanings. Yet, as long as we fail to develop an epistemological infrastructure which supports investigation of these complexities, we cannot develop an understanding of the wider networks which constituted past written meaning or properly evaluate its cultural significance. Likewise, archaeological thought on decision-making processes, choice and intentionality also stands to contribute to research on the selection of writing materials, and the choices past people made for how to write, read, view or otherwise engage with written surfaces.

However we understand material practice in general, in any given case study we need to ask both who were the practitioners and how they practised. Here we come up against another set of problematic terms - literacy, reading and writing - on which there is a substantial literature. In the more linguistically oriented studies devoted to the subject of literacy there is a strong emphasis on 'reading' and 'writing', understood very much in present day terms (see Collins and Blot 2003 for an overview). Archaeologists and ancient historians have devoted much time to discussion of the extent of literacy in any given society (by which they usually mean the number of people who could read and write, rather than what is indicated by these terms; see, for instance, Harris's seminal work Ancient Literacy (Harris 1989) and the responses of a number of other scholars (Beard et al. 1991). However, the kind of approach adopted in this volume requires the reconsideration of definitions of both 'writer' and 'reader' and also to consider a wider range of practitioners than can be encompassed in these terms, for instance the people who made the artefacts, who may well have been different from the people who wrote on them.

When thinking about 'writers' we need to be explicit about whether we mean the people who wielded the pen, stylus, brush or chisel, or those who composed the message. These may have been the same people, but equally may not have been, especially where materials were used that required complex technologies and specialist artisans. We also need to consider the role of people commissioning an inscription who might not themselves have been able to write or read. For instance, the production of a bronze tablet to be put up in a public place, as known from the Roman world, might involve four different types of maker: a member of the political or religious establishment to commission the work, a literate bureaucrat to compose the text, a bronzesmith to fashion the tablet, and probably a different bronze worker to chisel the letters. Of these people, only the bureaucrat had to be literate, in the sense of understanding the sense of the text. The person who produced the actual writing (whom one might think reasonable to label the 'writer') might have been copying a prototype and have had little understanding of what the text meant. Maureen Carroll (2009: 47) mentions a splendid example of this, the Roman stone funerary inscription from Annaba that reads hic iacet corpus pueri nominandi (here lies the body of the boy ... insert name): the letter cutter had failed to notice that he was meant to insert a specific name!

'Readers' are equally difficult to define. We might identify fully literate (in the modern sense) readers, who could understand texts completely; we might also consider those who could perhaps read a little, but could not decipher a text in detail. There would be others who could not read at all but who 'consumed' writing through oral performance by others. Or those who did not even do this but who viewed the texts and knew they were important in some way. And who were the readers of hidden inscriptions (those on the inside of sealed tombs or even built into the construction itself)? If the intended viewers were dead people or supernatural beings, in what sense were they 'readers'? 


\section{Outline of the Book}

Having formulated the theme and methodological framework for the conference in late 2008 / early 2009, we were astounded by the scale and range of the responses we received to the call for papers - a testament to the interest and need to bridge the gap between philologically and archaeologically oriented studies of writing. Twenty-five papers in total were presented at the annual conference of the Institute of Archaeology, University College London, held in May 2009. These were delivered by staff and graduate students from a range of museums and universities across the UK and from around the world, including the US, Europe and Australia.

A selection of these papers appear in this volume, exploring writing practices from the ancient past to more recent contexts, although there is a particular concentration on writing from the ancient Mediterranean region, and the Aegean in particular. This concentration reflects the responses to the original conference invitation and subsequent choices by both contributors and editors; interest in the materiality of writing is more developed in some fields than others. The diversity and asymmetry of temporal contexts and cultural areas represented may seem unconventional compared with conferences or publications for the traditional subject areas of textual or material cultural studies. Nevertheless, when mapping out a new research landscape differential engagement is to be expected - as methodological intersections between writing and material culture are identified and explored and new configurations which encourage fuller theorisation and sustained critical discourse are developed. Under these circumstances, which can be defined as a phase of ongoing epistemological reassessment, we feel that breadth should precede depth.

Fifteen ${ }^{2}$ case studies set writing and related symbolic modes in relation to material practice including writing production, consumption and related performance and sensory experience. These studies critically explore traditional definitions and treatments of 'writing' to develop new perspectives and approaches that offer more holistic understandings of this evidence type. The volume also includes this Introduction and an Epilogue.

In spite of our emphasis on new perspectives and approaches, we have nevertheless organised the chapters in a somewhat conventional manner, generally following a geographical ordering with exceptions to allow for the treatment of subject matter according to chronological sequence. Starting with South and Meso-America, case studies shift to the Near Eastern heartland of writing and then return westwards to the Mediterranean, and on to Great Britain. We end with a methodological paper relating to the conservation of writing. This collection is not necessarily intended to be read in order, but rather dipped into at points of relevance, concern, and curiosity - hopefully prompting the reader to engage with less familiar evidence, and provoking consideration of analytical methods and interpretive frameworks that might be fruitfully adopted, adapted, or otherwise used to broaden the reader's perspective.

Indeed, over the decades, explorations of the various facets of 'written' objects make clear that the question of what constitutes 'writing' in a given society must remain an open one if it is to be understood in the terms of its users, and need not be confined to notation systems that are related directly to spoken language. In his study of the khipus in Andean society, Frank Salomon looks at the functional implications of recording with fibre. He argues that khipus functioned not as fixed texts but as operational devices or simulators - visual models rather than verbal transcriptions. Whether this counts as writing is less important than recognising "graphical excellence" (Tufte 1983: 182) in one of its less familiar forms.

Sarah Jackson places similar emphasis on the importance of a context sensitive approach. Mayan image and text intersect and intertwine in profound ways and it is difficult if not ill-advised to attempt to separate them. In practice, writing may not be distinct from other symbolic modes, or may encompass multiple symbolic functions. Too rigid a definition may preclude identification of significant and meaningful relationships, hence the importance of taking account of this 
evidence type in terms of situated practice. Jackson interprets her examples of Mayan writing as an "orientational technology" that serves to locate people in culturally defined landscapes, especially socio-political landscapes that include both experiential and imagined aspects.

Roger Matthews discusses the earliest, and one of the longest-lasting, traditions of writing: the "cuneiform culture" of the ancient Near East. Initially developed as a system of writing on clay tablets and used mainly for accounting purposes, cuneiform also appears on many other media and was used for many different languages and a great variety of purposes. He shows how new research focussing on the materiality of cuneiform texts is addressing questions about the role(s) of writing in different Near Eastern societies.

Rachael Sparks considers how during the $2^{\text {nd }}$ millennium BCE the southern Levant became the meeting point for a number of different writing traditions, involving different languages and scripts, but also different materials, tools, and practices, as well as different contexts of use. She shows how this mixture of influences and practices allowed an unusual fluidity and experimentation with writing that led to the local development of alphabetic scripts.

Helène Whittaker investigates material practices associated with all the scripts of the Aegean Middle and Late Bronze Ages - Hieroglyphic, Linear A and Linear B (c.2000-1200 BCE) in the context of palace bureaucracies. While concentrating on the materials employed and the techniques used for writing, in addition to script and language, she also demonstrates the relationships between context, text-content and the forms of material expression employed in constructing wider social meaning.

Sarah Finlayson also examines the three main writing systems of the Bronze Age Aegean in terms of the relationships between writing and its material supports. She adopts the basic hypothesis that the shape of objects which bear writing derives from the use to which they, object + writing, are put and the shape changes as this purpose changes. Focussing particularly on Linear A, which appears on a diverse range of writing supports, she assesses whether the different materials and objects relate in an organised way to the different uses they were put to, e.g. clay tablets to administrative purposes and 'libation tables' to ritual use.

Georgia Flouda focusses on Minoan writing (therefore excluding Linear B) and considers how different forms of expression worked, examining features such as material, shape, mode and direction of writing, as well as archaeological context. She demonstrates different trajectories for Hieroglyphic (seals, tablets, and other types) and Linear A respectively. She draws heavily on semiotic theory especially the work of Peirce, suggesting, for instance, that the isolated 'pictographic' signs first appearing on the seals were understood as semasiographic codes.

Helena Tomas also considers Aegean Bronze Age writing, but concentrates on one specific phenomenon: the practice of cutting clay tablets (with a special emphasis on Linear B). A detailed study of the location of the cuts and the way they were carried out suggests two different motivations. Whereas the page-shaped tablets were probably cut in order to remove unnecessary clay (probably to keep tablet size to a minimum), elongated tablets may have been cut for the purpose of rearranging the information (for instance, a reclassification according to the origin of the people registered).

With particular emphasis on Greek-speaking and -writing areas, Alan Johnston examines the influence of different surfaces and the use of brush, pen and chisel on the appearance of text in the early centuries ( $c .800$ to $300 \mathrm{BCE}$ ) of alphabetic writing. In addition to writerly issues, aids for the reader such as the boustrophedon system and use of interpuncts are also considered for the tensions they exhibit between aesthetic concerns and practicality.

Whereas writing is often understood to be a system developed by elite members of society to consolidate authority, and fix social meanings and relationships, Kathryn Piquette explores late $4^{\text {th }}$ and early $3^{\text {rd }}$ millennium вСE evidence from Egypt which reveals the dynamic unfolding and reformulation of early writing and related imagery. Focussing on funerary labels of bone, 
ivory and wood, stone vessels and a stele, Piquette considers the implications of practices of unmaking, re-making, and incompletion.

Stephen Kidd considers a single document, a $3^{\text {rd }}$-century вСЕ Greco-Egyptian letter inscribed on papyrus: a bilingual letter, written in Greek and Demotic. The second language is used specifically to detail a dream which the author, Ptolemaios, claims has to be described in Egyptian. The change of language also involved a change in script, associated with very different material practices. So the shift was informed not only by the languages as they were processed in the author's brain, but also by the scripts themselves as they were experienced in the motions of his hands, the movement of his eyes, and the material objects he used to interact with these scripts.

Elisa Perego considers 'Situla Art', an elaborate figurative decorative style found mainly on bronze objects during the $7^{\text {th }}$ to $3^{\text {rd }}$ centuries BCE around the head of the Adriatic Sea. She adopts the concept of iconic literacy - the skill of producing and interpreting images - to study situla art and compare it to traditional textual literacy, which develops at approximately the same time in parts of the region. She argues that both inscribed objects and the products of situla art were employed to negotiate and promote the social role of high-ranking individuals. However, because true writing and situla art rarely occur on the same objects, she suggests that they were seen as alternative systems of communication, and that situla art, which was not restricted to the users of a single spoken language, could be understood over a wider geographical area.

Ruth Whitehouse's chapter is also based on evidence from the north Italian Iron Age and looks specifically at tomb markers of different types and inscribed in two different languages, Etruscan and Venetic. In contrast to traditional studies concerned with languages and scripts, she concentrates on the different physical arrangements of the inscriptions on the stones and what these meant in terms of bodily movements and sensory engagements on the part of both the makers ('writers') and consumers ('readers') of the texts.

We then turn to Craig Cessford who examines $18^{\text {th }}$ - and $19^{\text {th }}$-century writing from the Grand Arcade site in Cambridge, England. He focusses on the ways in which material type, size, form and function of different kinds of artefact affect how writing was deployed. Cessford also considers why writing occurs incompletely or not at all on certain object types, highlighting a general yet critical issue for investigators of written culture - of accounting for absence alongside presence, and visibility as well as invisibility.

Elizabeth Pye draws our attention to the impact of the presence of writing, or the potential to reveal writing, on objects for decisions relating to conservation procedures and perceived values of objects. The common practice of prioritising the revealing of writing may lead to adverse effects on the preservation of the writing supports - a problem that may be alleviated by modern techniques of digital imaging. However, digital imaging produces its own problems, as computer hardware and software themselves require conservation.

Finally, John Bennet brings the book to a close with an overview of writing and its ancient material expressions as covered in the chapters in this volume, while also reflecting on changing materialities and practices associated with modern emerging writing technologies.

\section{Writing as Material Practice: Previous and recent research}

Since the inception of the conference in early 2008, its convening in mid-2009, and in the course of editing this volume, we have learnt of work on material aspects of writing relating, both ancient and modern, which were unfamiliar to us and which we would have been unlikely to discover through usual bibliographic search mechanisms. Nonetheless, at the time of writing, no booklength work exists that takes the materiality of writing as its central theme, nor is there one that draws together a wide range of examples from different cultural contexts. This does not mean 
that there is no interest in the subject - far from it - but research has been intermittent and dispersed. Traditionally writing has been almost exclusively the realm of philologists, linguists, historians and literary specialists who have been concerned primarily with issues of language and the meaning (in the sense of translation) of texts. Such work is vital, but as recent research is demonstrating, attentiveness to the relationship between scribal practice, materials and tools, and textual meanings is also essential (e.g. Taylor 2011). Other areas of textual studies such as book history and religious studies are increasingly recognising that writing is not a transparent medium of language which needs materiality only at its place of application or illustration, but that "... writing's very materiality influences the range of interpretive responses and receptions of the text" (Frantz 1998; see also O'Hara et al. 2002).

Within archaeology, 'writing' and other forms of 'visual culture's have remained peripheral to discussions of material culture and past human experience. Reconstructed material worlds are populated with pots, lithics and other implements, items of adornment and an array of other objects, but inscriptions, writings, documents, texts, manuscripts, and so on feature all too rarely. Similarly, charting change and continuity in the technologies of past societies represents a core area of archaeological research, and here too the technological aspects of writing production and use as material artefact only make brief appearances, if at all (e.g. Schiffer and Skibo 1987). That technological features and relationships are significant for understanding script appearance, meaning and function has long been recognised within papyrology (e.g. Tait and Leach 2000). The mechanics of writing, from tool use and material selection, as well as posture and the bodily movement of the scribe at work are important for understanding writing technologies. Writers may produce their materials and tools themselves, or acquire them from others (Palaima 1985: 102; 1988: 27; Quirke 2011: 280; Sjöquist and Åström 1991: 7, 20, 29-30; Taylor 2011: 7-12, 21-23). The importance of materiality and technology is also recognised within cuneiform studies. Jonathon Taylor (2011) has recently presented a survey of material aspects of cuneiform clay tablets. While sign morphology may be the primary vehicle of meaning expression, it can also be bound up with other material aspects, such as types of clay, their preparation and use as tablet cores or the sheets of finer clay wrapped around them, overall tablet shape, surface formatting, stylus shape and the techniques of incision or impression. Fuller consideration of writing materials and technologies are crucial to a holistic account of textual and related meanings, from dating to charting processes of change and continuity (Quirke 2011: 280), knowledge transfer and skills acquisition and processes of professionalisation, to aspects of writer or copyist social identity and relationships (e.g. Janssen 1987) within scribal and wider communities of practice. It is within this unfolding discourse that this volume aims to contribute momentum.

\section{Concluding Remarks}

This collection of papers explicitly addresses the roles of materials and materiality in the contexts of production and consumption of writing, as well as problems of scholarly documentation of writing and the incorporation of its material aspects. By uniting diverse researchers around the common theme of writing as material practice, it is clear that regardless of temporal, geographical or cultural context, investigation of graphical culture for its material qualities constitutes a rich and fruitful area of inquiry. We hope that this volume provides an invaluable resource for those seeking to develop their own research in this area, and for all with an interest in the phenomenon of 'writing' in its broadest sense.

\section{Notes}

${ }^{1}$ Contributors to this volume use these terms slightly different ways. 
${ }^{2}$ In assembling these chapters from authors using both American and British spellings, we have decided to let each author follow either convention, while maintaining consistency within each chapter.

${ }^{3}$ This term is used here with an awareness of the importance of other forms of sensory perception.

\section{References}

Andrén, A. 1998. Between Artefacts and Texts: Historical archaeology in global perspective. New York: Plenum Press. DOI: http://dx.doi.org/10.1007/978-1-4757-9409-0

Barrett, J. C. 2001. Agency, the Duality of Structure, and the Problem of the Archaeological Record. In Hodder, I. (ed.), Archaeological Theory Today. Cambridge: Polity Press, 141-164.

Beard, M., Bowman, A. K., Corbier, M., Cornell, T., Franklin Jr., J. L., Hanson, A., Hopkins, K. and Horsfall, N. (eds) 1991. Literacy in the Roman World (Journal of Roman Archaeology Supplementary Series 3). Ann Arbor, MI: Department of Classical Studies, University of Michigan.

Bottéro, J. 1992. Mesopotamia: Writing, reasoning and the gods. Chicago: University of Chicago Press.

Bottéro, J. 2000. Religion and Reasoning in Mesopotamia. In Bottéro, J., Herrenschmidt, C. and Vernant J. P. (eds), Ancestor of the West: Writing, reasoning and religion in Mesopotamia, Elam and Greece. Chicago: University of Chicago Press, 3-66.

Bourdieu, P. 1977. Outline of a Theory of Practice (translated by Richard Nice) (Cambridge Studies in Social and Cultural Anthropology 16). Cambridge University Press. DOI: http://dx.doi. org/10.1017/CBO9780511812507

Carroll, M. 2009. 'Vox tua nempe mea est': Dialogues with the dead in Roman funerary commemoration. Accordia Research Papers 11(2007-2008): 37-76.

Collins, J. and Blot, R. K. 2003. Literacy and Literacies: Texts, power, and identity (Studies in the Social and Cultural Foundations of Language 22). Cambridge: Cambridge University Press. DOI: http://dx.doi.org/10.1017/CBO9780511486661

David, N. and Kramer, C. 2001. Ethnoarchaeology in Action. Cambridge: Cambridge University Press.

Dobres, M. A. 2000. Technology and Social Agency: Outlining a practice theory for archaeology. Maiden, MA: Blackwell Publishers.

Fahlander, F. and Kjellström, A. (eds) 2010. Making Sense of Things: Archaeologies of sensory perception (Stockholm Studies in Archaeology 53). Stockholm: Postdoctoral Archaeological Group Publications.

Foucault, M. 1979. Discipline and Punish: The birth of the prison. Harmondsworth: Peregrine Books.

Frantz, N. P. 1998. Material Culture, Understanding, and Meaning: Writing and picturing. Journal of the American Academy of Religion 66(4): 791-816. DOI: http://dx.doi.org/10.1093/ jaarel/66.4.791

Gardner, A. 2003. Seeking a Material Turn: The artefactuality of the Roman empire. In Carr, G., Swift, E. and Weekes, J. (eds), TRAC 2002: Proceedings of the $12^{\text {th }}$ Annual Theoretical Roman Archaeology Conference, Canterbury 2002, 1-13. Oxford: Oxbow.

Gardner, A. 2004. Introduction: Social agency, power, and being human. In Gardner, A. (ed.), Agency Uncovered: Archaeological perspectives on social agency, power, and being human. London: UCL Press, 1-15.

Gibson, J. J. 1979. The Ecological Approach to Visual Perception. Boston, MA: Houghton Mifflin.

Giddens, A. 1979. Central Problems in Social Theory. London: Macmillan.

Giddens, A. 1984. The Constitution of Society: Outline of the theory of structuration. Berkeley: University of California Press.

Harris, W. V. 1989. Ancient Literacy. Cambridge, MA: Harvard University Press. 
Hawkes, C. 1954. Archaeology Theory and Method: Some suggestions from the Old World. American Anthropologist 56(2): 155-168. DOI: http://dx.doi.org/10.1525/aa.1954.56.2.02a00020

Hodder, I. 2000. Agency and Individuals in Long-Term Processes. In Dobres, M.-A. and Robb, J. E. (eds), Agency in Archaeology. London: Routledge, 21-23.

Ingold, T. 2007. Materials Against Materiality. Archaeological Dialogues 14(1): 1-16. DOI: http:// dx.doi.org/10.1017/S1380203807002127

Janssen, J. J. 1987. On Style in Egyptian Handwriting. Journal of Egyptian Archaeology 73: 161167. DOI: http://dx.doi.org/10.2307/3821527

Jay, M. 2002. That Visual Turn: The advent of visual culture. Journal of Visual Culture 1(1): 87-92. DOI: http://dx.doi.org/10.1177/147041290200100108

Little, B. J. (ed.) 1992. Text-Aided Archaeology. Boca Raton, FL: CRC Press.

Matthews, R. 2003. The Archaeology of Mesopotamia: Theories and approaches. London: Routledge.

Mitchell, W. J. T. 2002. Showing Seeing: A critique of visual culture. Journal of Visual Culture 1(2): 165-181. DOI: http://dx.doi.org/10.1177/147041290200100202

Moreland, J. 2001. Archaeology and Text. London: Duckworth.

Moreland, J. 2006. Archaeology and Texts: Subservience or enlightenment. Annual Review of Anthropology 35: 135-151. DOI: http://dx.doi.org/10.1146/annurev.anthro.35.081705.123132

O'Hara, K. P., Taylor, A., Newman, W. and Sellen, A. J. 2002. Understanding the Materiality of Writing from Multiple Sources. International Journal of Human-Computer Studies 56(3): 269305. DOI: http://dx.doi.org/10.1006/ijhc.2001.0525

Palaima, T. G. 1985. Appendix. In Åström, P. and Sjöquist, K.-E. (eds), Pylos: Palmprints and palmleaves (Studies in Mediterranean Archaeology, Pocket book no. 31). Göteburg: Paul Åströms Förlag, 99-107.

Palaima, T. G. 1988. The Scribes of Pylos (Incunabula Graeca 87). Rome: Edizioni dell'Ateneo.

Piquette, K. E. 2007. Writing, 'Art' and Society: A contextual archaeology of the inscribed labels of Late Predynastic-Early Dynastic Egypt. Unpublished PhD dissertation, University College London.

Piquette, K. E. 2008. Re-materialising Script and Image. In Gashe, V. and Finch, J. (eds), Current Research in Egyptology 2008: Proceedings of the ninth annual symposium, which took place at the KNH Centre for Biomedical Egyptology, University of Manchester, January 2008. Bolton: Rutherford Press Limited, 89-107.

Piquette, K. E. forthcoming. Scribal Practice and an Early Dynastic Stone Vessel Inscriptions: Material and aesthetic implications. In Dodson, A., Johnston, J. J. and Monkhouse, W. (eds), A Good Scribe and an Exceedingly Wise Man: Studies in honour of W. J. Tait. London: Golden House.

Piquette, K. E. 2013. Structuration and the Graphical in Early Dynastic Culture. In Dann, R. J. and Exell, K. (eds), Egypt: Ancient histories, modern archaeologies. Amherst, NY: Cambria Press, 51-99.

Quirke, S. 2011. Agendas for Digital Palaeography in an Archaeological Context: Egypt 1800 вC. In Fischer, F. Fritze, C, and Vogeler, G. (eds), Kodikologie und Paläographie im digitalen Zeitalter 2 - Codicology and Palaeography in the Digital Age 2 (Schriften des Instituts für Dokumentologie und Editorik 3). Norderstedt: Books on Demand (BoD), 279-294. http://kups. ub.uni-koeln.de/id/eprint/4354 [accessed 18 October 2013]

Schiffer, M. B. and Skibo, J. M. 1987. Theory and Experiment in the Study of Technological Change. Current Anthropology 28(5): 595-622. DOI: http://dx.doi.org/10.1086/203601

Schlanger, N. 1996. Understanding Levallois: Lithic technology and cognitive archaeology. Cambridge Archaeological Journal 6(2): 231-254. DOI: http://dx.doi.org/10.1017/ S0959774300001724

Sjöquist, K.-E. and Åström, P. 1991. Knossos: Keepers and kneaders (Studies in Mediterranean Archaeology, Pocket book no. 82). Gothenburg: Paul Åströms Förlag. 
Skeates, R. 2010. An Archaeology of the Senses: Prehistoric Malta. Oxford: Oxford University Press. Smith, M. 2008. Visual Culture Studies. Los Angeles: Sage.

Tait, J. and Leach, B. 2000. Papyrus. In Shaw, I. and Nicholson, P. (eds), Ancient Egyptian Materials and Technology. Cambridge: Cambridge University Press, 227-253.

Taylor, J. 2011. Tablets as Artefacts, Scribes as Artisans. In Radner, K. and Robson, E. (eds), Oxford Handbook of Cuneiform Culture. Oxford: Oxford University Press, 5-31. DOI: http://dx.doi. org/10.1093/oxfordhb/9780199557301.013.0001

Tite, M. S. 2008. Ceramic Production, Provenance and Use - A review. Archaeometry 50(2): 216-231. DOI: http://dx.doi.org/10.1111/j.1475-4754.2008.00391.x

Tufte, E. 1983 The Visual Display of Quantitative Information. Cheshire, CT: Graphics Press.

Wenger, E. 1998. Communities of Practice: Learning, meaning, and identity. Cambridge: Cambridge University Press. DOI: http://dx.doi.org/10.1017/CBO9780511803932

Whitehouse, R. D. 2008. The Materiality of Writing: Case studies from first millennium BC Italy. McDonald Lecture. 19 November 2008; unpublished.

Whitehouse, R. D. 2012. Epilogue: Agency and writing. In Englehardt, J. (ed.), Agency in Ancient Writing. Boulder, CO: University Press of Colorado.

Woodward, A. and Leach, P. with contributions by Bayley, J. 1993. The Uley Shrines: Excavation of a ritual complex on West Hill, Uley, Gloucestershire, 1977-9 (Archaeological report [English Heritage] 17). London: English Heritage in association with British Museum Press. 